$109-123$

\title{
LA NOCIÓN DE LA "DIVINIDAD" MAPUCHE SEGÚN LUIS DE VALDIVIA EN SERMÓN EN LENGUA DE CHILE (1621): INTERPRETACIÓN ETNOCÉNTRICA DE LA OTREDAD INDÍGENA
}

The notion of Mapuche "divinity" according to Sermón en lengua de Chile (1621) by Luis de Valdivia: an ethnocentric interpretation of indigenous otherness

Nataly Cancino-Cabello*

Resumen

Sermón en lengua de Chile (1621), del jesuita granadino Luis de Valdivia, incluye, en su versión en español, varios términos en mapudungun, de estos 'huecuvoe', 'marepuante' y 'pillan' se explican como "equivalentes" a las divinidades del cristianismo. En este trabajo, apoyándonos en la etnohistoria, evaluamos su correspondencia con los referentes de la cultura mapuche y concluimos que se trata de conceptos que han sufrido un proceso de desplazamiento semántico motivado por la visión de mundo del locutor. De este modo, se genera un discurso falible en su efectividad argumentativa.

Palabras clave: Sermones, Léxico mapuche, Religión, Luis de Valdivia.

Abstract

Sermón en lengua de Chile (1621) written by Spanish Jesuit Luis de Valdivia incorporates vocabulary from the Mapudungun language. Several terms in Mapudungun such as 'huecovoe', 'marepuante' and 'pillan', are explained as "equivalents" of Christian divinities. Based on ethnohistorical studies, in this paper we analyze the effective concept relationships and meaning in the Mapuche culture. The main findings suggest that these concepts have undergone a semantic change as a result of the writer's worldviews. Thus, a fallible discourse is generated in its argument effectiveness.

Key words: Sermons, Mapuche lexicon, Religion, Luis de Valdivia.

\section{INTRODUCCIÓN}

A inicios del siglo XVII Luis de Valdivia, jesuita granadino que llegó a Chile en 1593, propone un cambio en la estrategia española de enfrentamiento bélico con los mapuches. Señala que en lugar de las armas se debe buscar la paz y el diálogo, de modo que se consiga una "conquista espiritual" y se termine con los altos costes económicos y humanos que acarreaba la guerra (Díaz Blanco). Su plan se ejecuta con la autorización de la Corona desde 1606 (aunque se institucionalizó en 1612), pero ya a finales de la segunda década del siglo comenzó su declive, tanto por la oposición de los políticos y los encomenderos como por la resistencia de los indígenas (Mires). Valdivia viaja, 
entonces, a España, entre 1620 y 1621, para solicitar que se continúe con la estrategia que ha propuesto, pero debido a que en su Orden no era bien vista su injerencia política, lo envían a Valladolid, donde permanecerá hasta su muerte (Díaz Blanco).

Allí imprime Sermón en lengua de Chile (1621), obra bilingüe mapudungunespañol, la que, aunque no se menciona, está basada en el Tercero Catecismo (1585) del III Concilio de Lima (Cancino-Cabello, El Tercero) y se presenta como acomodada a la capacidad de los indios infieles del Reino de Chile (De Valdivia, Sermón). Es decir, para su elaboración se ha considerado la conformación de auditorio y, por tanto, se adecua a la realidad cultural y la capacidad mental que el locutor adjudica a los alocutarios ${ }^{1}$ (mapuches).

De forma habitual, los hablantes construimos el discurso a partir de condicionamientos extradiscursivos. Este recurso está presente en la predicación cristiana desde sus inicios, fundamentalmente por medio de las parábolas, la que se fundamentan en una distinción de los niveles de capacidad de los oyentes, según pudieran conocer o no directamente el mensaje divino (Murphy). San Agustín de Hipona retoma este fundamento y destaca el carácter adaptativo del discurso:

una es la intención del que dicta algo, pensando en un lector futuro, y otra la del que habla en presencia directa de un oyente [...]. Y también importa mucho, cuando hablamos, si son muchos o pocos los que escuchan, si doctos o ignorantes, o entremezclados; si son habitantes de la ciudad o campesinos, o si ambos están mezclados; o si se trata de una asamblea formada por todo tipo de hombres. Es inevitable, en verdad, que unos de una manera y otros de otra influyan en el que va a hablar y enseñar, y que el discurso proferido lleve como la expresión del sentimiento interior del que lo pronuncia, y que por la misma diversidad impresione de una manera u otra a los oyentes, ya que estos se ven influidos, cada uno a su modo, por su presencia (Agustín 400/1998, 489-490 [15, 23]).

El Santo Padre institucionaliza la diferenciación del auditorio en la oratoria sagrada, recurso retórico que se ejecutará a lo largo de la historia de la predicación. En las obras catequéticas de la lingüística misionera americana, y en la búsqueda de una mayor efectividad del discurso, esta herramienta funciona desde la delimitación conceptual de los indígenas en consideración de su pertenencia etnocultural.

En Sermón en lengua de Chile se manifiesta, entre otros mecanismos, mediante la inclusión en la versión española de léxico mapuche (particularmente del ámbito religioso), del que analizamos aquellos términos que expresan la noción de "divinidad". Estos nos muestran que, a pesar del intento de adaptación discursiva, el hablante no ha logrado comprender a cabalidad su sentido, por lo que no hay coincidencia en el referente que designan. Más bien son una interpretación que ha realizado con el filtro ideológico que aplicó a todo lo que vio y oyó y que no le

\footnotetext{
${ }^{1}$ Usamos el concepto alocutario, en el sentido de Ducrot y Todorov, como los receptores que se tienen en cuenta para la producción del discurso.
} 
permitió una comprensión de la "otredad" a la que se enfrentaba. Estamos, por tanto, ante un caso de desajuste intercultural que hace falible la argumentación.

\section{LA CULTURA MAPUCHE A FINALES DEL SIGLO XVI E INICIOS DEL SIGLO XVII}

Desde hace algunas décadas, varias disciplinas lingüísticas (análisis del discurso, pragmática, lingüística del texto y aplicada, entre otras) apelan por la consideración del contexto en el estudio de objetos verbales. Creemos que, desde una perspectiva metodológica, es necesario establecer lazos interdisciplinarios (CancinoCabello, Los textos) que nos permitan comprender mejor la relación mental entre los interlocutores (Van Dijk). En nuestro caso, los universos religiosos que se enfrentan en el discurso no se encuentran igualmente documentados, porque mientras abundan fuentes sobre el cristianismo (y sus manifestaciones en América), la reconstrucción etnohistórica mapuche se ve sometida a impedimentos metodológicos. A pesar de lo anterior, y ya presentada la obra desde la acción de su autor, revisamos las principales manifestaciones de dicha cultura en el ámbito religioso, a finales del siglo XVI e inicios del XVII, cuando toma contacto con ella Luis de Valdivia.

Los mapuches ocuparon un amplio territorio, que llegó a extenderse desde Coquimbo ( $30^{\circ}$ latitud sur) hasta el extremo sur de la isla de Chiloé ( $43^{\circ}$ latitud sur) (Böning). Presentaban, además, particularidades étnicas de acuerdo con la ubicación geográfica de sus asentamientos ${ }^{2}$ que, en la práctica, constituyen grupos con una identidad colectiva y dominio sobre el conjunto territorial, por lo que son soberanos y autónomos $^{3}$ (Martínez Neira). En total eran un millón de individuos, por lo que se trataba de una zona densamente poblada, con un nomadismo mínimo. La mayoría se ubicaba a partir del río Maule (fuera del dominio y de la influencia incaicos), en la falda marítima de la cordillera de Nahuelbuta y en la falda oriental, hacia los valles. En lo que actualmente es La Araucanía había cerca de 500 mil mapuches (Bengoa).

A pesar de las diferencias, todos los grupos hablaban la misma lengua, como lo reconoce Luis de Valdivia en el Prólogo de su Arte (1606). El mapudungun, 'lengua de la tierra', es polisintética y aglutinante: "el significado total de la forma verbal [por ejemplo] es resultado de la combinación estratificada de los significados individuales de los elementos constituyentes" (Salas, 69).

Como decíamos, hacer la etnohistora de este pueblo resulta particularmente complejo, pues este ejercicio se realiza tras el proceso de aculturación que produjo el contacto con los conquistadores y cuyas consecuencias fueron el olvido o las

\footnotetext{
${ }^{2}$ Aunque es usual encontrar entre los investigadores la identificación de cada parcialidad con un área geográfica determinada, para Martínez Neira más bien se trataba de unidades ecológicas. Ambos planteamientos son confluyentes en cuanto la geografía determinará aspectos como los medios de subsistencia, ya que las variantes fueron producto de "la necesidad de adaptarse a diferentes sistemas ecológicos" (Casanova, 32).

${ }^{3}$ Por tanto se diluye la noción de uniformidad cultural en el territorio, idea que se debe a los estudios históricos de inicios del siglo XX (Parentini Gayani).
} 
variaciones morfológicas de prácticas y creencias ancestrales, en todos los niveles de la práctica cultural, de los que en Sermón en lengua de Chile es posible apreciar con claridad las consecuencias en los planos organizativo y religioso.

A lo anterior hay que sumar que nos enfrentamos a una cultura ágrafa, cuya tradición recae sobre la oralidad (Salas Astrain, Lo sagrado), por lo que nuestras fuentes más antiguas (y del periodo que nos interesa) son los registros de los primeros cronistas y misioneros. Es decir, son escritos acerca de los mapuches que obedecen al posicionamiento ideológico de los conquistadores (propio de la época y de su situación), por lo que dejan la duda respecto de la comprensión efectiva de la cultura vernácula (Foerster).

En el caso del tema religioso, en particular nos enfrentamos a la inexistencia de términos en el español que den cuenta de la concepción mapuche del mundo (Latcham). Además, entre las expresiones de esta cultura no encontramos formas "idolátricas" o, por lo menos, no se hallan representaciones materiales (tangibles física y visualmente) de sus creencias (Valenzuela, $\mathrm{La} C \mathrm{Cruz}$ ), por lo que la arqueología poco puede decir sobre las primeras épocas de su cosmovisión. Esta situación se origina en el hecho de que en la religión mapuche no se reconocían divinidades (Latcham), sino más bien la presencia constante de nges ('seres tutelares', 'dueños de ambientes, animales u objetos') en todo el entorno (Barreto). El hecho de que cada elemento poseyera un ngen dispersaba el poder y otorgaba un carácter sagrado a todo lo que estaba al alcance del hombre, por lo que no había sitios "especiales" (Curivil).

A juicio de Latcham, antes de la llegada de los españoles existían dos formas de expresión religiosa en el pueblo mapuche: el totemismo y el culto a los antepasados. El totemismo se hallaba en un estado transitorio, por lo que no fue observado por los cronistas y misioneros, y desapareció en el siglo XVIII. El "tótem" es un objeto, ser o fenómeno con cuyas características se identifica un colectivo -a partir de una filiación real o imaginaria- $\mathrm{y}$ de donde deriva su nombre. Este ser totémico, que protegía a todos los miembros del clan, era llamado Ngenüncan, término derivado de ngen, 'dueño de', y del verbo üncan, 'amparar, defender'.

Respecto del culto a los antepasados, para Latcham, se trataría de la verdadera religión que practicaban los mapuches. Los antepasados se representaban en el pillan, "a quien ofrecían sacrificios y otras ofrendas propiciatorias, implorando su protección y ayuda" (Latcham, 27). Estos ritos no contenían ningún acto de adoración, sino que evitaban la ira del pillan, que podía producirse si se faltaba a alguna regla totémica o no se cumplía con algún rito y se manifestaba por medio de fenómenos naturales que ocurrían al instante, pues, según Guevara, el pillan era una potencia generativa, responsable del bienestar material.

Este último autor reconoce una tercera forma de expresión religiosa: el culto al sol. A su juicio, tenía un origen incaico e influyó en la cultura mapuche a partir de su inserción en el fondo totémico de las parcialidades del norte. Sin embargo, en el 
centro su expansión fue escasa y nula, en el sur, donde habría llegado sin cuerpo metódico y como representaciones fragmentarias e inconexas.

En lo anterior, describimos un universo cultural con creencias que difieren de las propias del cristianismo, desde donde fueron interpretadas por los cronistas y misioneros. Este hecho contribuyó a la aculturación (mediante la inculturación) que ha sufrido el pueblo mapuche. Una de las manifestaciones de este proceso ocurre en Sermón en lengua de Chile con la noción de "divinidad", que el locutor de esta obra traslada desde la religión cristiana a la mapuche.

\section{LÉXICO RELIGIOSO MAPUCHE EN EL SERMONARIO: LAS “DIVINIDADES”}

El contacto entre términos importados y otros vernáculos conduce a varios desplazamientos semánticos en nociones afines o antagónicas que crean nuevos significados (Correa). Esto se produce porque, en las situaciones de colonización, "los referentes de las palabras de las dos lenguas que entran en contacto suelen cambiar modificando su significado en virtud de los ajustes necesarios a la nueva realidad" (Parodi, 479-480). En particular, las modificaciones semánticas en el plano religioso se producen como consecuencia del contacto con el cristianismo y afectan a las creencias indígenas en un nivel simbólico (Curivil).

En la versión española de Sermón en lengua de Chile se introducen términos del mapudungun en la búsqueda de una mejor efectividad de la dimensión argumentativa de la obra (Cancino-Cabello, Mundo indígena), pero esta argumentación se vuelve falible pues traslada a su universo términos de otro, de otra lengua, que no son equivalentes a aquellos que quiere representar ${ }^{4}$. Los desplazamientos semánticos del sermonario se producen por la propia concepción de mundo eurocéntrica del locutor, quien no logró comprender las prácticas indígenas sino que se las explicó como formas cercanas a (o deformadas respecto de) lo que él conocía, en un ejercicio de (des)encuentro con la otredad indígena que, en el fondo, definió la Conquista y la Colonia americanas. Este hecho influye en la inclusión de los términos huecuvoe, marepuante y pillan. En torno a ellas (aunque no se ofrecen anotaciones metalingüísticas sistemáticas) se describen algunas prácticas intraculturales, como el ser objeto de adoración, honra, reverencia e invocación, lo que les da el carácter de "divinidad" propio del cristianismo, por lo que se convierten en sus "equivalentes" en la cultura mapuche.

Sin embargo, estas informaciones no representan la relación que realmente se pretende establecer, pues en la cultura indígena se trata, más bien, de formas ligadas a

\footnotetext{
${ }^{4}$ Aedo evidencia la falta de correspondencia entre términos del español y del mapudungun en la traducción de los sermones a esta última lengua. Observa que De Valdivia (Sermón) intenta adecuar vocablos indígenas a nociones del cristianismo, provocando problemas de interpretación por parte de los oyentes. Por ejemplo, “[...] 'pecado' no era un concepto que formara parte de la cultura mapuche, intentando encontrar algún equivalente Valdivia lo traduce por 'huerilcan'; sin embargo, en mapudungun este término se refiere al rechazo de algo causado por enfado y a negarse a comer por un sentimiento de rabia" (Aedo, 106).
} 
una creencia del mundo espiritual respecto de las enfermedades (huecuvoe), a un tótem (marepuante) y al culto a los antepasados (pillan). Estos términos pueden concurrir en un mismo pasaje, como en el fragmento (1):

(1) [...] qualquier cofa $\{3\}$ q es contraria a lo q Dios $\{4\}$ manda, es fin duda pecado. \{5\} Nombrar al Pillan al Ma-\{6\}reupuante, al Huecuvoe, $\{7\}$ y reuerenciarlos, creer lo q $\{8\}$ los hechizeron dizē, y obe-\{9\}decellos, es tābien pecado (De Valdivia, Sermón, 71).

A estos seres se les atribuye el ser objeto de una acción de carácter verbal, cuya realización es relevante en la dimensión ritual del cristianismo practicante y que se manifiesta mediante el verbo nombrar con el significado de 'invocar'. Además, a ellos se les reverencia y obedece, por lo que, como decíamos, equivalen a los seres "divinos" del panteón cristiano.

De Valdivia (Sermón) no solo expone a los alocutarios indígenas la visión de mundo que les adjudica, sino que también la evalúa, presentándoles sus prácticas como erróneas, con lo que también invierte la valoración intracultural que el pueblo mapuche hace de sí mismo. En el ejemplo (2) esta situación se produce con una autoridad, los ancianos:

(2) Los viejos os de-\{17\}zian, $q$ el Pillā eftà en el cie\{18\}lo, y el Huecuvoe en la tie-\{19\}rra, y mar. Engañananos e- $\{20\} 1 \mathrm{los}$, no ay tal, no, q es men$\{21\}$ tira, no digays tal, q es fin $\{22\}$ fundamento (32).

Para reforzar su argumentación, el locutor se basa en la "incapacidad" para "quitar los pecados" de las que considera "divinidades" indígenas. Es decir, traslada al pensamiento mapuche una noción de la que carecía y la usa como argumento para denostar sus creencias (Cancino-Cabello, Mundo indígena). Posteriormente, señala que estos "seres" no existen, afirmando así su tesis con una prueba que no puede someterse a comprobación, con lo que impone su autoridad sobre el alocutario, de modo que la argumentación se transforma en manipulación (3):

(3) El Pillā, ni el Ma-\{21\}reupuāte, ni el Huecuvoe, \{22\} no pueden quitar los peca-\{23\}dos, ni pueden falir con la $\{24\}$ fangre q fe hazen vros ne$\{25\}$ ges, los pecados de los hom $\{26\}$ bres. Todas eftas cofas q os $\{27\}$ dezian vanamente, sō gran $\{28\}$ des mentiras, y engaños.

\{29\} 8 No ay Mareupuāte, $\{30\}$ ni Huecuvoe, ni cofa algu-\{31\}na q fea Pillā, ô Mareupuā-\{32\}te, ni Huecuvoe (De Valdivia, Sermón, 72).

Por otra parte, la creencia en estos "seres" se califica como una inspiración demoniaca (4), acusación propia de las tesis con las que se justificó toda la Conquista (Crespo) y de las que el sermonario de De Valdivia es un ejemplo. La argumentación se refuerza atribuyendo a los receptores un comportamiento: en caso de haber tenido la información que ahora se les ofrece, habrían modificado antes su conducta: 
(4) No os $\{32\}$ engañen hijos mios todas las $\{33\}$ vezes que honrays al Pillan \{34\} y le nombrays, y cada, y quā \{35\} do que ador[*Jys al Huecu$\{36\}$ voe, y le nombrays, adorays $\{37\}$ a eftos diablos, $y$ los refpe-\{38\}tays, porque el diablo enga-\{39\}ñô a vueftros viejos, dizien-\{40\}do que fe llamaua Pillan y $\{42\}$ Huecuvoe, que $f$ huniera-\{p44\}\{1\}des fabido vofotros, que es $\{2\}$ el diablo efte que llamays $\{3\}$ Pillan no le hunierades $\{4\}$ de auer adorado, porque al $\{5\}$ diablo le foleys aborrecer $\{6\}$ pues quando os enajays con $\{7\}$ alguno le llamays mal diablo $\{8\}$ quien es efte mal alhue, fino $\{9\}$ el diablo (De Valdivia, Sermón, 43-44).

El locutor insta a los oyentes al abandono de las tradiciones que ha descrito y lo hace poniendo en su voz este compromiso, como parte de una oración cristiana. El cambio de la situación enunciativa favorece la argumentación, pues la responsabilidad de acabar con las expresiones religiosas de la cultura mapuche queda puesta en boca del alocutario, lo que invierte su rol ante su cultura, pues, al comprometerse a dejar de creer, se convierte en un agente de su propia transformación. De ese modo, el mapuche atenta en contra del ser mapuche:

(5) A Señor $\{18\}$ Iefu Chrifto, tu eres nuef- $\{19\}$ tro Padre, y nueftro Dios, $\{20\}$ y nueftro bienhechor. Pedi $\{21\}$ mofte el perdō de nueftros $\{22\}$ pecados: pefamos de anerte $\{23\}$ ofendido. Ten mifericordia $\{24\}$ de nofotros miferables, y $\{25\}$ por tu preciofa fangre, y $\{26\}$ muerte, faluanos. A ti como $\{27\}$ a nueftro verdadero Dios, $\{28\}$ folamente adoramos, y co- $\{29\}$ mo a Maeftro del cielo, en $\{30\}$ ti folo creemos. Y como a $\{31\}$ vnico Saluador, y Redentor $\{32\}$ nueftro, en ti folo efpera$\{33\}$ mos. De aqui adelante no $\{34\}$ adoraremos mas al Pillan, $\{35\}$ ni al Huecuvoe, ni creemos $\{36\}$ las mentiras fin fundamen-\{37\}to q dezian los viejos, y he-\{38\}chiceros (De Valdivia Sermón, 29).

Estos casos son desplazamientos semánticos que se producen en el texto desde la cosmovisión del locutor, pero que, al estar dirigidos a los mapuches, se convierten en promotores de una imagen de sí mismos que no se corresponde con lo que son. Con ello, Sermón en lengua de Chile se constituye en un discurso que recoge y crea determinadas percepciones sobre el ser mapuche que terminan negándolo y conviertiéndolo en el no deber ser en su propia cultura.

\section{LAS “DIVINIDADES"}

En los ejemplos (1) al (5) vemos que es usual la aglutinación de términos religiosos del mapudungun bajo la idea de "divinidad". Sin embargo, en el sermonario cada concepto se identifica con capacidades particulares. Pensamos que esto obedece a una forma "adaptada" de trasladar a tierras americanas el proceso de especialización en los ámbitos de acción que se llevaba a cabo en Europa con los santos cristianos (Valenzuela, El escenario barroco), aunque no fueran nociones equivalentes, lo que convierte este ejercicio en un mecanismo que fuerza la diversidad 
cultural para convertirla en una expresión puramente formal que facilita la manipulación.

\subsection{Huecuvoe}

Como acabamos de revisar, el enunciador adjudica a conceptos de la cultura mapuche características propias de los "seres" divinos del panteón cristiano. Este es el caso del término huecuvoe, al que se le atribuye el ser objeto de la práctica indígena del mismo modo que las divinidades cristianas son objeto de culto y devoción en esa religión (6):

(6) Quanto os párece q $\{29\}$ enojarâ a Dios, el Indio [...] que fue-\{34\}le nombrar por honrarle al \{35\} Huecuvoe, y le refpeE ta (De Valdivia, Sermón, 11).

Ahora bien, el desplazamiento semántico se produce por el desajuste entre el significado de este término mapuche en el interior de la cultura y la interpretación que el hablante realiza desde su propia visión de mundo. La noción de huecuvoe no se entiende como una divinidad, sino que se explica en la concepción de la muerte: para los mapuches, los decesos que no se producían en el campo de batalla o por accidente eran provocados por alguna acción invisible (Boccara), representada como una forma inmaterial que se instalaba en el cuerpo humano, el huecuvoe, cuyo significado en mapudungun puede conceptualizarse como 'el que obra desde afuera' (Barreto, 1992). La "sanación" se realizaba con una ceremonia liderada por la machi (Citarella), de modo que es posible que por medio del conocimiento (empírico) de aquellas prácticas De Valdivia haya concebido al huecuvoe como una divinidad.

\subsection{Marepuante}

$\mathrm{Su}$ inclusión en el sermonario también es un caso de desplazamiento semántico, en el que se identifica el marepuante como el 'hijo del sol'. En el texto esto se expresa mediante un proceso argumentativo basado en el razonamiento lógico deductivo-inductivo (7) a partir de la idea "el marepuante no existe". En este pasaje, el locutor, junto con presentar las nuevas informaciones a los alocutarios mapuches, expone también una particular forma de pensar, promoviendo o facilitando el proceso de aculturación al que este pueblo se ve sometido:

(7) No ay Mareupuāte, $\{30\}$ ni Huecuvoe, ni cofa algu-\{31\}na q fea Pillā, ô Mareupuā-\{32\}te, ni Huecuvoe. El fol no \{33\} tiene vida, pues lo q no tie$\{34\}$ ne vida, como puede tener $\{35\}$ hijo, y lo q no viue en $f i$ co $\{36\}$ mo puede dar vida a otros. \{37\} Tu lo q no tienes no lo das $\{38\}$ a otro, pues como fol q no \{39\} viue, ni tiene vida, puede $\{40\}$ dar vida a los hombres en-\{41\}teramente El fol no viue, ni $\{42\}$ fi tuuiera hijo viuiera fu hi $\{43\} j$, y fi el Mareupuante no $\{44\}$ tiene vida, como os auia de $\{45\}$ dar la vida a vofotros. Men $\{46\}$ tira es muy grande dezir q $\{47\}$ el fol tiene hijo. Y 
La noción de la "divinidad" mapuche según Luis de Valdivia en Sermón en lengua de Chile

como no $\{48\}$ ay Marecupuante, afsi es $\{49\}$ mentira dezir q ay Pillan (De Valdivia, Sermón, 72).

Esta mención en el sermonario es uno de los argumentos de Guevara para señalar la existencia del culto al sol entre los mapuches ${ }^{5}$. No obstante, de acuerdo con Latcham, el marepuante

[...] era con toda posibilidad el fundador del clan o de la tribu. Los indios al llamarse hijos de este, no hablaban en sentido figurado, sino como descendientes de este antepasado y con toda propiedad, porque a él le debían la vida por haber él originado su estirpe; en otras palabras era su pillán. A la vez, Marepuantü era hijo del sol, porque al ser este su tótem llevaría el apellido antü como sus antepasados. Para los araucanos esta idea era perfectamente lógica y verosímil pues el Marepuentü les había dado vida al engendrar su descendencia y era hijo del sol por ser de esa estirpe (Latcham, 616-617).

De este modo, la explicación De Valdivia (1621) no equivale a aquella práctica que se realizaba en el seno de la comunidad mapuche, sino que es una interpretación realizada desde su posición de misionero y agente político.

\subsection{Pillan}

De acuerdo con una relación recogida por Lozano, cuando Luis de Valdivia preguntó a un grupo de mapuches si el pillan era cuerpo o espíritu, ellos no supieron responderle y despertaron la compasión del jesuita. El misionero no sabía que, como indica Salinas Campos, esta era una pregunta incongruente para la racionalidad indígena. De todos modos, escribe desde la seguridad de quien ha interpretado correctamente aquello que ve y oye, aunque hoy podamos darnos cuenta que no siempre fue así, debido a que pretendió que todas las prácticas culturales mapuches cupieran en la explicación de su propia religión.

En el sermonario, el pillan se representa como la máxima divinidad, superior a todas las demás, hecho posible, en parte, gracias a la gran cantidad de veces y en los lugares disímiles en que se habría registrado esta voz. Así, presente a lo largo del territorio, de importancia para todos los grupos, no podía ser otra cosa que Dios. De hecho, Latcham señala que el culto al pillan estaba extendido por todas las parcialidades, pero cada familia tenía su propio pillan. Al regirse por filiación materna, en cada grupo se podían reconocer diversos pillanes, de acuerdo con la estirpe de cada miembro o al número de madres de diferente origen que había. Ello explicaría muchas de las contradicciones y vaguedades que sobre este concepto se forman los primeros españoles en aquellas tierras.

De acuerdo con el mismo autor, el mapudungun no contaba con un equivalente para el concepto español Dios, así que los misioneros se vieron obligados a buscarlo.

\footnotetext{
${ }^{5}$ Guevara señala que, si se trata de un tótem, este tuvo que haberse creado con posterioridad a la influencia inca, puesto que antü es una voz quechua. Si antes existió un tótem del sol, debió de haber llevado otro nombre.
} 
Creyeron que el más aproximado era pillan, pero sin comprenderlo, sino interpretándolo y adaptándolo a su propia manera de ver el mundo. Para Salas Astrain (Conquista), el atribuir a los indígenas la creencia en un ser supremo obedecía al interés de los misioneros por expandir la noción de un Dios monoteísta, ya que "si existía la idea de una divinidad superior, por más confusa que ella fuera, se abría un camino fecundo para hacer comprender el Dios cristiano" (Salas Astrain, Conquista, 271).

En el sermonario, la equivalencia entre el pillan y la 'divinidad' se produce por la finalidad persuasiva del sermón: terminar con las prácticas indígenas. Por ello, el locutor advierte a los mapuches que con la creencia en el pillan encontrarán la perdición y que la adoración que practican con esta "deidad" le corresponde, legítimamente, a la figura cristiana de Dios (8):

(8) Lo primero, teneys $\{28\}$ mucha necefsidad de creer $\{29\}$ en Iefu Chrifto, a ninguno $\{30\}$ q no creyere las cofas q los $\{31\}$ Chriftianos deuē creer, le $\{32\}$ feran perdonados fus peca- $\{33\}$ dos, ni feran hijos Dios. Y $\{34\}$ por efto todos los infieles \{35\} fe pierden, y fon quemados $\{36\}$ en el infierno, y todos los q \{37\} con reuerēcia nōbrā al Pillā $\{38\}$ Je perderan en el infierno, $y$ \{39\} feran caftigados fin fin, El \{40\} Pilla no merece adoración, \{41\} folo Dios es digno de fer a-\{42\}dorado, el es nueftro verda \{43\}dero, y fanto Padre, fiendo \{44\} criador de todo, el nos dio $\{45\}$ el fer de hōbres, el es Señor $\{46\}$ de todas las cofas, y N. S, Ie $\{47\}\}$ u Chrifto es digno de fer a\{48\}dorado (De Valdivia, Sermón, 24).

Además, De Valdivia en Sermón en lengua de Chile ofrece una codificación metalingüística sobre el pillan, entendido como 'volcán' (9), como una forma de informar pedagógicamente este significado a los misioneros jesuitas encargados de la prédica. Además, atribuye otros rasgos al pillan: su identificación con los truenos, el apoyo a los conas para el triunfo en las batallas, su ayuda para tener buenas cosechas y vida y ventura (10). Según Latcham, con esta descripción se presenta un ser benévolo, que ayuda y protege. Sin embargo, todas estas características son explicadas como expresión del demonio, por lo que se antiorientan, actualizando el modelo del no deber ser mapuche. Este ejercicio se debe a que el tipo textual exige la inclusión de las referencias al mundo cultural del otro para invertir su valor referencial entre los oyentes:

(9) Vofo- $\{$ p36 $\{1\}$ tros en el fer de hombres, $\{2\}$ foys mas q el Pillan (q es el $\{3\}$ Volc $\bar{a})$ y mas, q lo q llamays $\{4\}$ Huecuvoe, Dios folo es $\operatorname{dig}\{5\}$ no de fer adorado, y refpe- $\{6\}$ Etado verdaderamēte, y vo $\{7\}$ fotros le quitaftes la honra $\{8\}$ deuida a Dios, es lamenta- $\{9\}$ ble cofa (Valdivia 1621,36).

(10) Dize el diablo [...] q adoreys al Pillā \{27\} fin fundamento. Preguntal$\{28\}$ de al diablo, q cofa es el Pi-\{29\}llan? el dize muchas menti $\{30\}$ ras, porq no ay cofa alguna $q\{31\}$ fea realmēte Pillā, $q$ fi el dia $\{32\}$ blo no es Pillan, es cierto $q\{33\}$ no ay cofa alguna q fea Pillā. $\{34\}$ Dize el 
La noción de la "divinidad" mapuche según Luis de Valdivia en Sermón en lengua de Chile

diablo q el Pillā true\{35\}na en el cielo, y ayuda a pe-\{36\}lear a los conas: pero miente [...] no ay cofa q lo fea, fino $\{42\}$ es el diablo y el miente, por $\{43\} q$ fi el es el Pillan, el no true-\{44\}na, ni con fu voluntad viene $\{45\}$ la victoria de vna parte, y de $\{46\}$ otra [...]. porq Dios no fea ho $\left.{ }^{*}\right\}\{16\}$ rado, por effo dize fin funda $\{17\}$ mento, y con mentira, $q$ ado\{18\}reys al Pillan, y q el truena,

\{19\} 11 Dios folo haze q fal-\{20\}gan los fembrados, y el dia-\{21\}blo dixo lo q dezis vofotros $\{22\}$ que por mandado del Pilian $\{23\}$ nacen, $\hat{o}$ no nacē los fembra\{24\}dos, y que teniendo entrada \{25\} el Pillan, tendreys vida y vē \{26\}tura [...]. (Valdivia, Sermón, 44-45)

Valdivia no es el único autor que adjudica diversos significados al concepto pillan $^{6}$. Sin embargo, para Latcham, dicha multiplicidad no se corresponde con la práctica indígena real, sino con la interpretación que hicieron los cronistas y misioneros a partir de su propia ideología. En el sermonario, en efecto, la consideración disímil del mismo concepto se produce a partir de las ideas previas del locutor y que le sirven como guías para explicar(se) las prácticas con las que tuvo contacto.

\section{CONCLUSIONES}

Los términos religiosos del mapudungun se incorporan a la versión en español de Sermón en lengua de Chile con el fin de presentar contenidos de la cultura mapuche que no tienen equivalente en la última lengua. Si consideramos que se trata de un texto argumentativo (Cancino-Cabello, Mundo indígena), el léxico en mapudungun se introduce como una forma de generar un discurso más cercano al universo cultural vernáculo, facilitando el proceso de convencimiento. Este ejercicio se realiza de acuerdo con el tipo textual y los objetivos de la inculturación: se incorpora el mundo ajeno para describirlo en términos de "lo erróneo" y "lo negativo", utilizando, de ese modo, un recurso de antiorientación argumentativa. Por otra parte, la inclusión de estos conceptos también ofrece una función pedagógica para los jesuitas que oralizarían o tomarían los sermones como modelo, ya que podrían aprender aquellas creencias que el locutor adjudica a los alocutarios.

Con las palabras en mapudungun el hablante pretende construir una determinada imagen de sí mismo respecto de los otros: él conoce la cultura mapuche y, a partir de su conocimiento, la evalúa, posibilidad a la que no pueden acceder los receptores, excepto mediante el discurso del mismo enunciador. Se trata, por tanto, del incremento de una relación asimétrica de poder, que conduce a la superioridad de uno sobre los otros.

\footnotetext{
${ }^{6}$ Schindler señala que incluso en la actualidad no existe un significado consensuado para pillan.
} 
Con este trabajo aportamos a las líneas de investigación que promueven la inclusión del contexto en los estudios lingüísticos, de modo que apelamos por la consideración de criterios teóricos y metodológicos que nos permitan abordar producciones del pasado a partir de las relaciones situadas entre los participantes de la comunicación, porque finalmente "cada texto funciona siempre en su contexto histórico y ese contexto histórico es el que determina en cada momento la función de cada comunicación lingüística" (Ridruejo, 539).

Universidad de Playa Ancha*

Centro de Estudios Avanzados Traslaviña 450, Viña del Mar (Chile) nataly.cancino.cabello@gmail.com

\section{OBRAS CITADAS}

Aedo Fuentes, María Teresa. "El doble discurso de la frontera: los textos catequísticos de padre Luis de Valdivia". Acta Literaria 30 (2005): 97-110.

San Agustín. "La catequesis a principiantes". Obras completas de San Agustín. Escritos varios 1, XXXIX. Edición de Lope Cilleruelo. Madrid: Biblioteca de Autores Cristianos, 400/1998:425-534.

Barreto, Óscar. Fenomenología de la religiosidad mapuche. Buenos Aires/Bahía Blanca: Centro Salesiano de Estudios "San Juan Bosco"/Archivo Histórico Salesiano de la Patagonia Norte, 1992.

Bengoa, José. Historia del pueblo mapuche. Siglos XIXY XX. Santiago de Chile: Sur, 1985. Boccara, Guillaume. Los vencedores. Historia del pueblo mapuche en la época colonial. Antofagasta/San Pedro de Atacama: Universidad Católica del Norte/Instituto de Investigaciones Arqueológicas y Museo R.P. Gustavo Le Paige S.J., 2007.

Böning, Ewal. El concepto de pillán entre los mapuches. Buenos Aires: Centro Argentino de Etnología Americana, 1995.

Cancino-Cabello, Nataly. "Los textos no contemporáneos del español de América. Algunas reflexiones sobre lingüística e interdisciplinariedad". Cuadernos de la Alfal 2 (2011): 186-195. En línea:

http://mundoalfal.org/sites/default/files/revista/02_cuaderno_015.pdf.

Consulta: 01/12/12.

“El 'Tercero Catecismo' del III Concilio de Lima: un modelo textual para la evangelización americana". Ponencia presentada en $9^{\circ}$ Congreso Internacional de la Asociación de Historia de la Lengua Española, Cádiz, España, 2012a.

"Mundo indígena y cristianismo en sermones usados para evangelizar al pueblo mapuche (siglo XVII)". Actas del VIII Congreso Internacional de Historia de 
La noción de la "divinidad" mapuche según Luis de Valdivia en Sermón en lengua de Chile

la Lengua Española, II. Emilio Montero Cartelle, ed. Madrid: Arco/Libros, 2012b:1827-1836.

Casanova Guarda, Holdenis. "El rol del jefe en la sociedad mapuche prehispánica". Araucanía, Temas de Historia Fronteriza. Sergio Villalobos, Holdenis Casanova, Horacio Zapater, Luis Carreño y Jorge Pinto. Temuco: Universidad de La Frontera, 1989:31-45.

Citarella, Luca, Ana María Conejeros, Bernarda Espinoza, Ivonne Jelves, Ana María Oyarce y Aldo Vidal. Medicinas y culturas en La Araucanía. Santiago de Chile: Sociedad Trafkin/Programa de Atención Primaria en Salud/Cooperación Italiana/Sudamericana, 2000.

Concilio Provincial de Lima. Tercero Cathecismo y exposicion de la DoEtrina Christiana, por Sermones. Para que los cvras y otros miniftros prediquen y enfeñen a los Yndios y a las demás perfonas. Conforme a los que en el sancto Concilio Prouincial de Lima Je proueyo. Impresso con licencia de la Real Audiencia. Cuidad de los Reyes [Lima]: Antonio Ricardo, 1585.

Correa, Gustavo: "El espíritu del mal en Guatemala. Ensayo de semántica cultural". Guatemala indigena VI/2-3 (1971): 5-110.

Crespo Cuesta, Eduardo Daniel. Continuidades medievales en la conquista de América. Pamplona: Universidad de Navarra, 2010.

Curivil Paillavil, Ramón Francisco. La fuerza de la religión de la tierra. Una herencia de nuestros antepasados. Santiago de Chile: Universidad Católica Silva Henríquez, 2007.

De Valdivia, Luis. Sermon en lengva de Chile, de los mysterios de nvestra santa fe catholica, para dedicarla a los indios infieles del reyno de Chile, dividido en nveve partes pequeñas, acomodadas a fu capacidad. Valladolid: [Jeronimo de Murillo (?)]. Biblioteca Nacional de Chile, Sala Medina: SM 167.2 (microfilm), 1621.

_ Arte, y gramatica general de la lengva que corre en todo el Reyno de Chile, con vn Vocabulario, y Confelfionario. Compueftos por el Padre Luys de Valdivia, de la Compañía de Jefus, en la Prouincia del Piru. Ivntamente con la Doctrina Chrisftiana y Cathecifmo del Concilio de Lima en Efpañol, y dos traducciones del en la lengua de Chile, que examinaron y aprobaron los dos Reverendifsimos feñores de Chile, cada qual la de fu Obifpado. Lima: Francisco del Canto, 1606.

Díaz Blanco, José Manuel. Razón de Estado y buen gobierno. La Guerra Defensiva y el imperialismo español en tiempos de Felipe III. Sevilla: Universidad de Sevilla, 2010.

Ducrot, Orwald y Tzvetan Todorov. Diccionario enciclopédico de las ciencias del lenguaje. Buenos Aires: Siglo XXI, 1974.

Foerster, Rolf. Introducción a la religiosidad mapuche. Santiago de Chile: Universitaria, 1993. 
Guevara, Tomás. Historia de Chile. Chile Prehispánico, I. Santiago de Chile: Balcells \& Co, 1925.

Latcham, Ricardo E. "La organización social y las creencias religiosas de los antiguos araucanos". Publicaciones del Museo de Etnología y Antropología de Chile, III. Santiago de Chile: Cervantes, 1924:245-868.

Lozano, Pedro. Historia de la Compañía de Jesús en la Provincia del Paraguay, I. Madrid: Viuda de Manuel Fernández, 1754.

Martínez Neira, Christian. "La territorialidad mapuche lafquenche durante los siglos XVI y XVII". Tierra, desarrollo y desarrollo indígena. Temuco: Instituto de Estudios Indígenas, Universidad de La Frontera, 1995:103-110.

Mires, Fernando. La colonización de las almas. Misión y conquista en Hispanoamérica. Buenos Aires: Libros de la Araucaria, 2006.

Murphy, James J. La retórica en la Edad Media. Historia de la teoría de la retórica desde San Agustín hasta el Renacimiento. México DF: Fondo de Cultura Económica, 1986.

Parentini Gayani, Luis Carlos. Introducción a la etnohistoria mapuche. Santiago de Chile: Dirección de Bibliotecas, Archivos y Museos/Centro de Investigaciones Barros Arana, 1996.

Parodi, Claudia. "La semántica cultural: un modelo del análisis del contacto de lenguas". V Encuentro Internacional de Lingüistica en Acatlán. Pilar Máynez y María Rosario Dosal, eds. México DF: UNAM, 2007:479-492.

Ridruejo, Emilio: "Problemas metodológicos en pragmática histórica". Actes du $X X I V^{e}$ Congrès International de Linguistique et de Philologie Romanes, III. David Trotter, ed. Tübingen: Max Niemeyer Verlag, 2007:533-552.

Salas, Adalberto. El mapuche o araucano. Fonología, gramática y antología de cuentos. Madrid: Mapfre, 1992.

Salas Astrain, Ricardo: "Conquista, traducción y lenguaje misionero en el siglo XVI". Mapocho 32 (1992):209-224.

_ Lo sagrado y lo humano. Para una hermenéutica de los símbolos religiosos. Estudios de filosofia de la religión. Santiago de Chile: San Pablo, 1996.

Salinas Campos, Maximiliano. "El evangelio, el imperio español y la opresión contra los mapuches: el padre Luis de Valdivia en Chile, 1593-1619”. Misticismo y violencia en la Temprana Evangelización de Chile. Jorge Pinto Rodríguez, Maximiliano Salinas y Rolf Foerster. Temuco: Universidad de La Frontera, 1991: 71-167.

Schindler, Helmut. Acerca de la espiritualidad mapuche. München: Verlagsbuchhandlung, 2006.

Valenzuela Márquez, Jaime. 'El escenario barroco y los 'Soldados de Cristo' en la religiosidad colonial del siglo XVII". Mapocho. Revista de Humanidades y Ciencias Sociales 37 (1995):151-167. 
La noción de la “divinidad” mapuche según Luis de Valdivia en Sermón en lengua de Chile

— "La cruz en la cristianización jesuita de Chile meridional: signo, significados y paradojas (1608-1655)". La mediación lingüístico-cultural en tiempos de guerra: cruce de miradas desde España y América. Gertrudis Payàs y José Manuel Zavala, eds. Temuco: Universidad Católica de Temuco, 2012: 189-216.

Van Dijk, Teun A. Discurso y contexto. Un enfoque sociocognitivo. Barcelona: Gedisa, 2012. 